\title{
Narrative Review of the objective analysis of long-term outcome of the Ponseti technique: experience from Dallas
}

\author{
B. Stephens Richards^ \\ Department of Orthopaedic Surgery, Chief Medical Officer, Texas Scottish Rite Hospital, University Texas Southwestern, Dallas, Texas, USA \\ Correspondence to: B. Stephens Richards MD. Texas Scottish Rite Hospital, 2222 Welborn Street, Dallas, Texas 75219, USA. \\ Email: steve.richards@tsrh.org.
}

\begin{abstract}
In 2001, Texas Scottish Rite Hospital for Children (TSRH) prospectively began a clubfoot database that included all of our patients with clubfeet who were willing to enroll. Nonoperative treatment, primarily the Ponseti method, was utilized. This article summarizes the experience from Dallas treating idiopathic clubfeet using the Ponseti technique, and is based on previously published studies utilizing information from the database. Patient clinical outcomes were defined as "good" (plantigrade foot achieved either with or without a percutaneous heel-cord tenotomy), "fair" (a plantigrade foot that required a limited procedure, such as tibialis anterior tendon transfer or posterior release), or "poor" (a plantigrade foot that required posteromedial release). Nearly $95 \%$ of idiopathic clubfeet obtained initial correction using the Ponseti technique, but relapses occurred and by age two years $24 \%$ needed some surgical intervention, usually limited procedures. Use of Dimeglio's rating system before treatment strongly correlated with the probability of a "good" outcome at two years. Objective measurements of brace wear compliance (iButton) in those who reached age two years with "good" outcomes demonstrated an unexpected pattern of diminishing use of the foot abduction orthoses over the first two years of brace wear. By the 18-month period of brace wear, 1/3 patients wore the orthoses less than 6 hours per day, and nearly half of the patients wore the orthoses less than 8 hours per day. Between ages 2-5 years, nearly $21 \%$ of the corrected clubfeet at age two years needed limited procedures to maintain/regain plantigrade positioning. Lateral weight-bearing radiographs between 18-24 months were not helpful in predicting future relapse in these patients, and are no longer routinely obtained. Following these patients for normal development is important, as nearly $9 \%$ of infants initially presenting as idiopathic clubfeet were eventually found to have another disorder including neurological, syndromic, chromosomal, or spinal abnormalities. We continue to emphasize the need to devote great attention to detail when using the Ponseti method in an effort to optimize the clinical outcomes.
\end{abstract}

Keywords: Clubfoot; Ponseti; Texas Scottish Rite

Submitted Oct 29, 2020. Accepted for publication Jan 19, 2021.

doi: $10.21037 / \mathrm{atm}-20-7180$

View this article at: http://dx.doi.org/10.21037/atm-20-7180

\section{Introduction}

In 2001, Texas Scottish Rite Hospital for Children (TSRH) in Dallas prospectively began a clubfoot database that included all of our new patient referrals with clubfeet who were willing to enroll. Though predominantly idiopathic in nature, all types of clubfeet were included. Early on we utilized both the Ponseti method and the French physiotherapy method for the treatment of infants with clubfeet. Prior to the initiation of the database, all of the medical staff had received personal training in the techniques from both Dr. Ponseti of Iowa and Dr. Dimeglio of Montpellier, France. Over time, the Ponseti method

$\wedge$ ORCID: 0000-0002-3513-2754. 


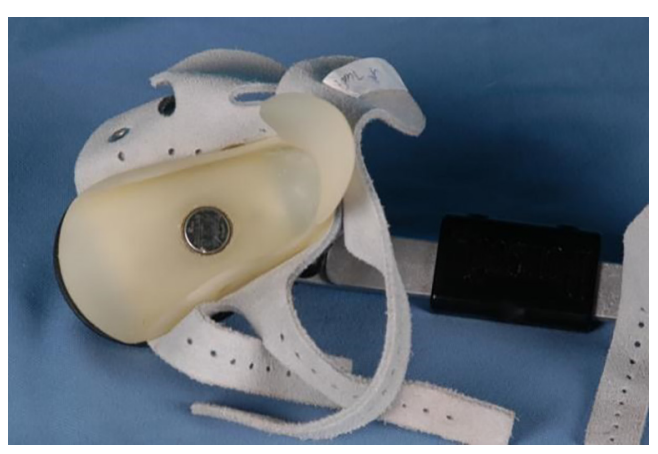

Figure 1 The foot abduction orthoses have been equipped with a temperature data logger imbedded in the sole of a shoe.

became the predominant method utilized, and today nearly all of the infants presenting with clubfeet to TSRH undergo treatment using Ponseti casting. To the present time, there have been 1,118 patients ( 1,585 clubfeet) enrolled in the database that have been treated with the Ponseti method. Data that has been collected includes demographics, clinical history, clinical outcomes, brace wear compliance data from temperature sensors, surgery that is required, radiographs, and gait studies. The range of patient follow-up found in our publications range from 2 to 17.6 years.

The key question for this review topic: what has the TSRH experience been using the Ponseti treatment program for idiopathic clubfeet? A number of studies on our institution's treatment results have previously been published. For this article, focus will be on a summary of our clinical experience using the Ponseti method for idiopathic clubfeet (1-14). I present the following article in accordance with the Narrative Review reporting checklist (available at http://dx.doi.org/10.21037/atm-20-7180).

The TSRH experience on the functional evaluation of clubfoot treatment with gait analysis is presented in another article by LA Karol and KA Jeans in this special clubfoot issue for the Annals of Translational Medicine.

\section{Methods}

Before beginning treatment, the clubfeet were evaluated using the Dimeglio severity scale by either orthopaedic surgeons or nurse practitioners familiar with the rating system (15). We have found the use of this rating system before treatment provides prognostic information for parents, as the clubfoot initial rating correlates with the probability of a good outcome (14). We found that the feet with moderate deformity had the best outcomes.
Early on, seven pediatric orthopaedic surgeons participated in the care at TSRH. Over time, an additional four pediatric orthopaedic surgeons joined in the care of clubfoot patients. For the treatment, physicians manipulated and positioned the feet for all plaster casts. Once treatment was started, adherence to Ponseti's protocol was strict until correction of the foot was achieved, including the performance of percutaneous heelcord tenotomies in the clinic setting. Tenotomies done in the clinic setting, as opposed to subjecting the $<3$-month-old infant to sedation in the operating room, have been advantageous in our experience (3). Once the Ponseti cast treatments were finished, all infants were placed in a foot abduction orthosis (open-toed straight-last shoes with a Denis Browne bar) to maintain the correction. Detailed instructions for brace wear were provided to the parents and caretakers. The brace was worn full-time for three months, with a return visit each month, and then at nighttime until the minimum age of two years. Clinic visits were scheduled every three months during the nighttime brace wear. In an effort to optimize compliance with brace wear, the nurse coordinator's contact information was provided so that any brace wear questions or concerns could be addressed expeditiously, with the goal being to limit unintended time spent out of the brace. If a clinic visit was missed, the family was contacted by telephone or certified mail in order to schedule a new appointment.

Since 2010, in an effort to objectively measure brace wear compliance, the foot abduction orthoses have been equipped with a temperature data logger imbedded in a shoe (Figure 1). Every 15 minutes, temperature was recorded, and this data was held in the button for 3 months. This data logger was, and continues to be, used for both the full-time bracing period and nighttime-only bracing period. Upon the patients' return to clinic, the data was downloaded in the orthotics department. Parents were not informed that compliance was being monitored, rather only that temperature was being assessed in the brace. Likewise, the clinicians were not informed, thereby avoiding bias to the patient from the provider. The orthoses were prescribed as described above. Any relapses of the clubfeet that needed further casting were recorded. Relapse was determined clinically by the provider, and defined as recurrent hindfoot varus or ankle equinus that did not allow dorsiflexion to neutral; or recurrence/persistence of forefoot adductus or cavus, or any combination thereof.

Patient clinical outcomes were defined as "good" (a plantigrade foot achieved either with or without a percutaneous heel-cord tenotomy), "fair" (a plantigrade 
foot that required, or was scheduled for, a limited posterior release, a tibialis anterior tendon transfer, and/or other limited surgery), or "poor" (a plantigrade foot that required, or was scheduled for, a complete posteromedial release) (8). A plantigrade foot is one in which the entire sole of the foot is on the ground when the leg is upright. To define a fair outcome, one or more limited procedures were performed. These included a posterior release which was undertaken when persistent ankle equinus remained despite a previous percutaneous heel-cord tenotomy, a tibialis anterior tendon transfer which was undertaken when there was persistent, strong, active supination of the foot, and other minor procedures such as repeat isolated tendoAchilles lengthening, plantar fascia release, or lateral column shortening. These procedures may have been performed individually, or in combination.

\section{Outcomes}

\section{At completion of casting}

In our 2008 report, when the cast treatments of 267 feet were completed, the initial correction rate was $94.4 \%$ (8). This initial correction rate is consistent with that found throughout North America and worldwide. Clinicians should expect that the idiopathic clubfoot deformity in an infant can be corrected initially with use of Ponseti's nonoperative method, acknowledging that there will be some exceptions such as severe clubfeet treated by clinicians inexperienced with the Ponseti method, or in teratologic clubfeet in infants initially thought to be idiopathic, but later diagnosed with other conditions such as distal arthrogryposis or neuromuscular abnormalities.

\section{At two years of age}

Though correction of the clubfoot deformity is very likely upon completion of the casting technique, maintenance of correction has proven to be more challenging. Of the 252 feet listed above that achieved initial correction, 93 of them (37\%) had a relapse within the first two years despite strong encouragement for reliable brace wear (8). Nonoperative correction was again pursued in these patients, with success in many. However, due to poor brace compliance again, further relapses occurred, and eventually 61 feet $(24 \%)$ underwent surgical intervention. Thirty-two of these 61 feet had limited procedures and 29 feet had full posteromedial releases.

As mentioned above, in 2010 we began objective assessment of the amount of daily hours of brace wear using the iButton. One goal of ours was to identify how many hours per night were actually needed to achieve successful nonoperative "good" outcomes by age two years. We were not successful in determining this threshold because those patients who relapsed did not wear the shoes and, as a result, had no data that could be compared to those who reached age two years with successful nonoperative "good" outcomes. However, in those with successful nonoperative outcomes, we did find that they tended to use the nighttime braces fewer and fewer hours over the course of the first two years (11). Examining 124 patients with 187 clubfeet that had "good" outcomes, we found that during the 0 - to 3-month full-time bracing interval, wear time averaged $19.8 \mathrm{hr} /$ day. After this period of full-time use, the nighttime brace wear initially was very good (11.9 hours). With every subsequent 3 -month interval however, the brace wear progressively decreased despite encouragement to maintain 12 hours per day use (9.6, 8.6, 7.9, and 7.7 hours). By the middle of the second year of brace wear, 1 of 3 patients wore the orthoses less than 6 hours per day, and nearly 1 of 2 patients wore the orthoses less than 8 hours per day. At the present time, we're investigating opportunities to improve brace wear compliance, and subsequent success. With 2019 POSNA-funded support, we're studying TSRH's BraceRite app which uses a Bluetooth enabled iButton in the shoe that allows parents to track easily-interpretable objective brace wear measurements on their smartphones.

\section{Beyond 2 years of age}

Three hundred and thirty-six patients with 504 idiopathic clubfeet who underwent Ponseti treatment and who achieved successful nonoperative outcomes at the age of two years (a "good" foot in a plantigrade position) were studied over an extended period of time (average 8.8 years, range, 5-17.6 years) to determine the rate of recurrence, and the timing and type of surgery that was ultimately necessary (12). Over time, 122 of these 336 patients (36.3\%) needed surgery. The most common procedures performed were limited (a la carte) in scope: tibialis anterior tendon transfer, posterior release, plantar fascia release, and repeat tendo-Achilles lengthening, either in isolation or in combination. Between ages 2-5 years, 79 of these 122 patients had surgery on 104 feet. Ninety of these feet had limited procedures and 14 feet had complete posteromedial releases. After the age of 5 years, an additional 43 patients had surgery, all of which consisted of limited procedures 
performed in isolation or in combination, except for 2 feet which needed complete posteromedial releases.

Today, with more experience gained through the years, we feel that before considering surgery, the need for these procedures can, and should, be minimized by recasting recurrent deformities using Ponseti method.

\section{Radiographs}

From 2001 until 2016, we obtained standing lateral radiographs of the treated feet between 18-24 months of age to assess the position of the hindfoot, and to determine if the radiograph would be predictive of late recurrence. For those with a "good" outcome at age two years, and were at least four years of age at follow-up, the radiographs obtained between 18-24 months of age were assessed for the talocalcaneal angle and the tibiocalcaneal angle. When studied, 211 patients with 312 clubfeet were evaluated, with the average age at the time of follow-up being 8 years (9). Three-fourths maintained a "good" outcome, but one-fourth of the clubfeet subsequently required limited surgery, or more, to re-gain or maintain a plantigrade foot. The tibiocalcaneal angle and talocalcaneal angle from standing lateral radiographs made at 18 to 24 months of age were not helpful in predicting future relapse in this group of patients. With this information, we no longer routinely obtain radiographs of the corrected clubfeet.

\section{Clubfoot patients initially thought to be idiopathic, but evolved differently}

Infants who are considered to be normal with idiopathic clubfeet when nonoperative treatment begins may later be diagnosed to have other complicating issues, and therefore will be "non-idiopathic" clubfoot patients. In an effort to determine the incidence of this occurrence, we studied 789 patients with 1,174 clubfeet, with followup $\geq 2$ years, who were thought to be idiopathic patients when treatment began (10). Seventy of these 789 patients $(8.9 \%)$ were eventually found to have another disorder including neurological, syndromic, chromosomal, or spinal abnormalities. When these 70 nonidiopathic patients were compared to the 719 idiopathic patients, we found that these patients' clubfeet could still be improved with nonoperative treatment which, in this study, consisted of either the Ponseti method or the French physiotherapy method. However, these nonidiopathic patients required more surgical intervention early (by age
2 years) and later (age, 5 years and above).

\section{Conclusions}

Over the past two decades, the Ponseti technique for the treatment of idiopathic clubfeet has made a profound impact on our institution's ability to care for these patients. Through our research, we have gained a greater appreciation about the short term and intermediate term clinical outcomes, actual brace wear compliance and the successful outcomes noted with lesser hours of daily wear, limited usefulness of routine radiographs, importance of regularly evaluating the younger patients for the presence of other abnormalities, and more. We continue to emphasize the need to devote great attention to detail when using the Ponseti method in an effort to optimize the outcomes.

\section{Acknowledgments}

Funding: None.

\section{Footnote}

Provenance and Peer Review: This article was commissioned by the Guest Editors (Federico Canavese and Alain Dimeglio) for the series "Clubfoot" published in Annals of Translational Medicine. The article has undergone external peer review.

Reporting Checklist: The author has completed the Narrative Review reporting checklist. Available at http://dx.doi. org/10.21037/atm-20-7180

Peer Review File: Available at http://dx.doi.org/10.21037/ atm-20-7180

Conflicts of Interest: The author has completed the ICMJE uniform disclosure form (available at http://dx.doi. org/10.21037/atm-20-7180). The series "Clubfoot" was commissioned by the editorial office without any funding or sponsorship. Dr. BSR reports grants from Pediatric Orthopaedic Society of North America, outside the submitted work. The author has no other conflicts of interest to declare.

Ethical Statement: The author is accountable for all aspects of the work in ensuring that questions related to the accuracy or integrity of any part of the work are 
appropriately investigated and resolved.

Open Access Statement: This is an Open Access article distributed in accordance with the Creative Commons Attribution-NonCommercial-NoDerivs 4.0 International License (CC BY-NC-ND 4.0), which permits the noncommercial replication and distribution of the article with the strict proviso that no changes or edits are made and the original work is properly cited (including links to both the formal publication through the relevant DOI and the license). See: https://creativecommons.org/licenses/by-nc-nd/4.0/.

\section{References}

1. Delgado MR, Wilson H, Johnston C, Richards S, Karol L. A preliminary report of the use of botulinum toxin type A in infants with clubfoot: four case studies. J Pediatr Orthop 2000;20:533-8.

2. Faulks S, Richards BS. Clubfoot treatment: Ponseti and French functional methods are equally effective. Clin Orthop Relat Res 2009;467:1278-82.

3. Hedrick B, Gettys FK, Richards S, et al. Percutaneous heel cord release for clubfoot: a retrospective, multicentre cost analysis. J Child Orthop 2018;12:273-8.

4. Noonan KJ, Richards BS. Nonsurgical management of idiopathic clubfoot. J Am Acad Orthop Surg 2003;11:392-402.

5. Richards BS, Johnston CE, Wilson H. Nonoperative clubfoot treatment using the French physical therapy method. J Pediatr Orthop 2005;25:98-102.

6. Richards BS: Congenital Talipes Equinovarus (Clubfeet): The French "Functional" Non-operative Treatment Method. J Foot and Ankle Surg (India) 2007;22:8-13.

7. Richards BS, Dempsey M. Magnetic resonance imaging

Cite this article as: Richards BS. Narrative Review of the objective analysis of long-term outcome of the Ponseti technique: experience from Dallas. Ann Transl Med 2021;9(13):1100. doi: 10.21037/atm-20-7180 of the congenital clubfoot treated with the French functional (physical therapy) method. J Pediatr Orthop 2007;27:214-9.

8. Richards BS, Faulks S, Rathjen KE, et al. A comparison of two nonoperative methods of idiopathic clubfoot correction: the Ponseti method and the French functional (physiotherapy) method. J Bone Joint Surg Am 2008;90:2313-21.

9. Richards BS, Faulks S, Razi O, et al. Nonoperatively Corrected Clubfoot at Age 2 Years: Radiographs Are Not Helpful in Predicting Future Relapse. J Bone Joint Surg Am 2017;99:155-60.

10. Richards BS, Faulks S. Clubfoot Infants Initially Thought to be Idiopathic, But Later Found Not to Be. How do They do With Nonoperative Treatment? J Pediatr Orthop 2019;39:42-5.

11. Richards BS, Faulks S, Felton K, et al. Objective Measurement of Brace Wear in Successfully PonsetiTreated Clubfeet: Pattern of Decreasing Use in the First 2 Years. J Am Acad Orthop Surg 2020;28:383-7.

12. Siebert MJ, Karacz CM, Richards BS. Successful Ponsetitreated Clubfeet at Age 2 Years: What Is the Rate of Surgical Intervention After This? J Pediatr Orthop 2020;40:597-603.

13. Steinman S, Richards BS, Faulks S, et al. A comparison of two nonoperative methods of idiopathic clubfoot correction: the Ponseti method and the French functional (physiotherapy) method. Surgical technique. J Bone Joint Surg Am 2009;91 Suppl 2:299-312.

14. Zhang W, Richards BS, Faulks ST, et al. Initial severity rating of idiopathic clubfeet is an outcome predictor at age two years. J Pediatr Orthop B 2012;21:16-9.

15. Diméglio A, Bensahel H, Souchet $\mathrm{P}$, et al. Classification of clubfoot. J Pediatr Orthop B 1995;4:129-36. 